\title{
Electronic borrow-back system of Colleges and Universities Digital Library Based on RFID
}

\author{
Li Hongwei, a Dou Zhiwu, 2,b \\ ${ }^{1}$ Library , Yunnan University of Finance and Economics 650221 Kunming, Yunnan \\ ${ }^{2}$ School of Business, Yunnan University of Finance and Economics 650221 Kunming, Yunnan \\ azhiwudou@163.com, b86372627@qq.com
}

Keywords: RFID; Library; Electronic borrow-back;

\begin{abstract}
In the network era, how to use the fast, accurate, detail and automation features of the network to provide efficient, high quality service to become the new problems faced by Universities library. On the basis of researching the characteristics and application of RFID technology, put forward to the electronic borrow-back system of colleges and universities library combining RFID technology and the electronic commerce mode. A detailed analysis of the system structure, function, principle, information flow and the implementation of system was given. The actual application validated that the system greatly improves the service efficiency, quality and level of colleges and universities library, which has the important meaning to the digital library integration development.
\end{abstract}

\section{Introduction}

Colleges and Universities library is the function department to meet the knowledge demand of staff and students, however, with the continuous expansion of college enrollment and the increasing of the book number in library, how to effectively play the function of libraries of colleges and universities to provide quality service for teachers and students has become the emphasis and focus to universities library digitalization development. The traditional library management procedures rely on staff, such as examination, borrowing and back. It is time-consuming and laborious, readers often have to wait in line, so library can not provide more effective services. Along with the system reform of colleges and universities, teachers will concentrate more time and energy to the teaching and scientific research, leaving less time in the library. How to use the fast, accurate, detailed and automation features of network to provide automatic, high quality service to readers become the new problems faced by Colleges and Universities library in the digital age.

Radio frequency identification (RFID) technology provides possible method to solve the above problems. Therefore, this paper presents a new method combining RFID technology and e-commerce technology to meet the problem.

\section{Related technology}

RFID is a non-contact automatic identification technology, mainly composed of the card reader and a RF tag. RFID automatically identifies target and access to relevant data through the RF signal, the identifying work without human intervention, which can greatly improve the work efficiency, suitable for high speed moving target identification and recognition of multiple targets at the same time.

The application of RFID technology is a focus for many countries in today. RFID applications fields include access control and security management, production and logistics management, medical, transportation, documents and books management and campus card ${ }^{[1-4]}$. 2003 IFLA General Conference information technology professional group took "library services to wireless technology -- the use of RFID" as an open discussion theme ${ }^{[5]}$. In the United States, Singapore, Britain, Germany, Sweden, Switzerland, Japan, South Africa and other places have a more mature and advanced RFID system, in which the United States has more than 300 universities libraries have installed RFID system. So far, more than 20 domestic small libraries have adopted the technique of RFID. Zhang Yuanyuan and Liu Jingao proposed the intelligent library system in 2007 [6]. 


\section{Systems analysis and design}

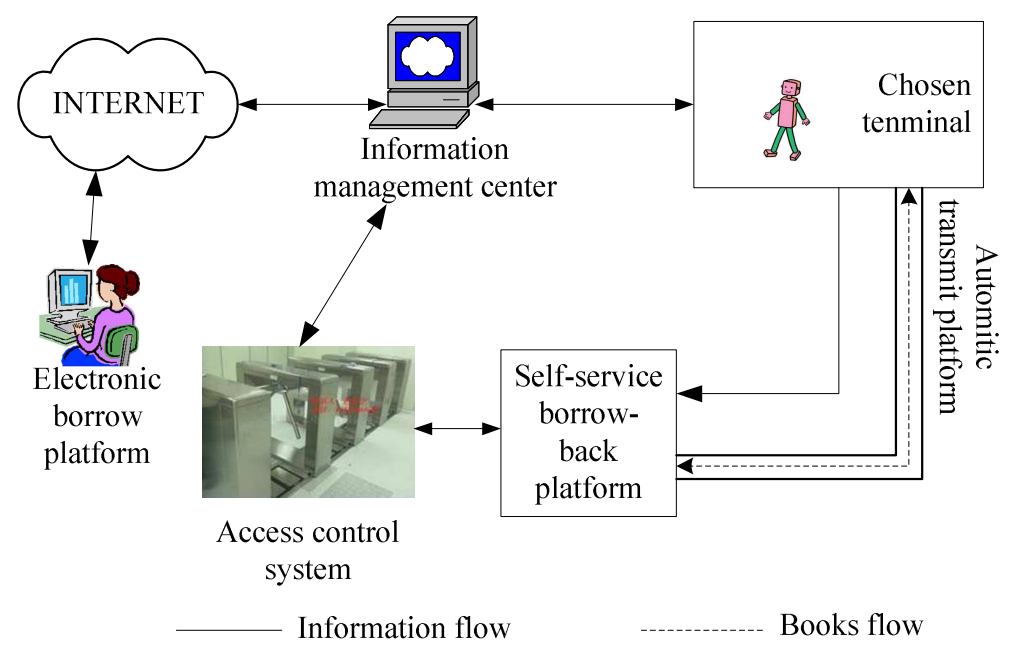

Fig.1 Colleges and universities library electronic borrow-back system

The system structure. With the continuous expansion of enrollment and the increasing of the book number in current universities, teachers and students spent more and more time to borrow books in the library. At the same time as the system reform of colleges and universities, teachers' working pressure is continuous increasing, a lot of time and energy for the teaching and scientific research, leaving less time in the library. Teachers and students hope to browse and select books target through the network in their spare time or at their leisure, electronically borrow, library received advance information will borrow the book ready, borrowers can take book from the self-service platform without entering the library directly. To achieve this goal, the system is composed of six parts: electronic library platform, information management center of digital library, choose terminal, automatic transmission platform, the self-service borrow-back platform, access control system.

The information flow in system. The system mainly involves two types of information flow, the information flow of borrowing book, another returning book information flow. Here only to borrowing book information flow as an example. Shows in Fig. 2.

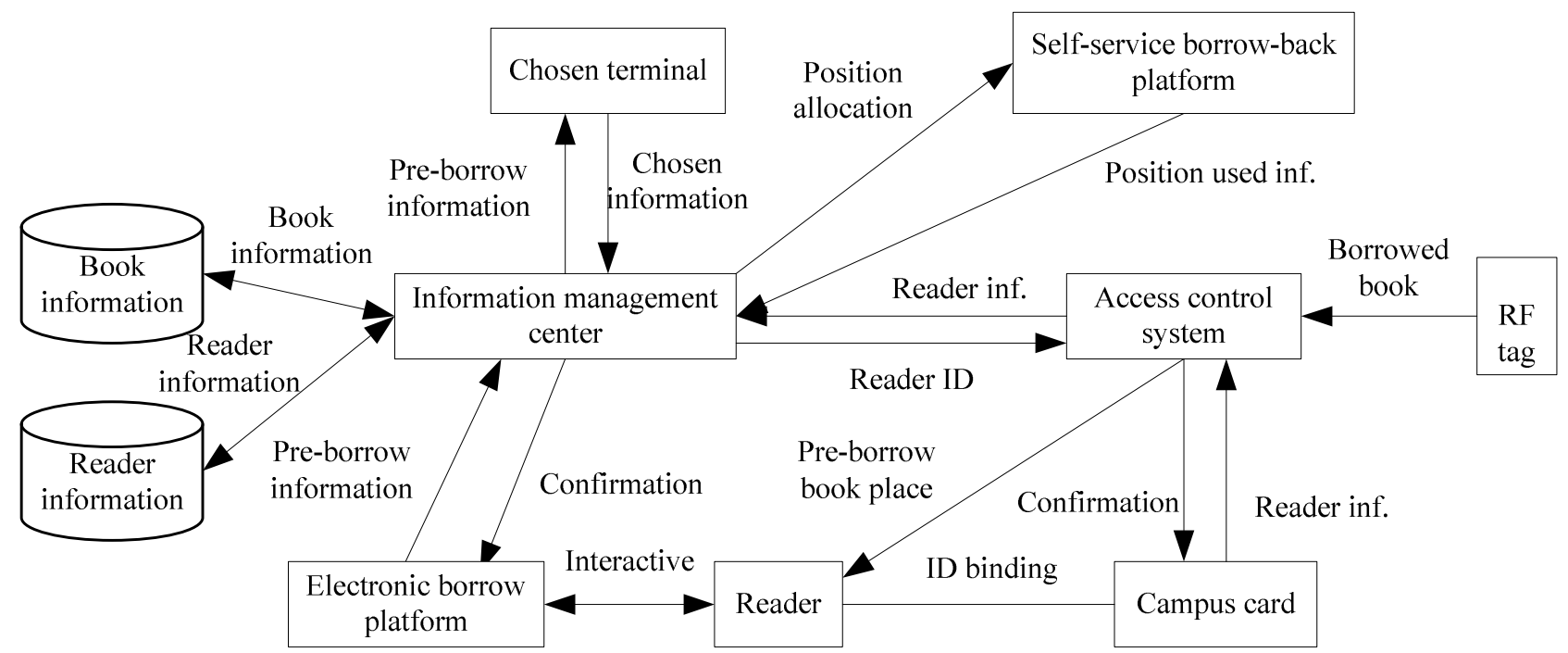

Fig.2 Electronic borrowing book information flow

Electronic borrowing book platform. Electronic borrowing book platform is an e-commerce platform that realizes the self-charging, editing information collection, authentication, book information display, personalized book recommendation and other functions. The reader can do registration, browse, select book, pre-borrow and interactive with library in the platform. 
The information management center of the digital library. The information management center of the digital library has two parts of functions: information management, such as add, delete, modify, query, the information including of book information, book state information, user information and information; another control, sending and receiving instruction and confirmation of books and readers, allocating position for books and other related processing.

Books choose terminal. The role of books choose terminal includes receiving pre-borrow information and returning-book information from the information center, sending corresponding operation confirmation message, books selection, books placed on the automatic transmission platform, book shelves etc..

Automatic transmission platform. This part finishes books automatic transmission, and coordinates with the self-service borrow-back books platform to place the books.

The self-service borrow-back books platform. The functions of the self-service borrow-back books platform are: to receive and transmit borrow-back books information; to read borrow-back books information; to receive and confirm the position distribution information of books, to put borrow-back books, and to provide borrow-back books temporary storage space.

When finishing the chosen and putting the chosen books onto the conveyor platform, the books chosen terminal will send the confirmation information to the information management center at the same time, after receiving the acknowledgement message information center will send location distribution information to the self-service platform. When the chosen books reached, the self-service borrow-back platform put the books to the pre-allocated location coordinating with transmitting platform. Pre-borrowed books general has a time limit of 48 hours, overtime automatically cancel pre-borrowed state and automatic transmission back to the library.

Access control system. The main function of access control system is reading and identifying the information of reader and books in-out of the library, writing state information to campus card, exchanging information with information center, and alarm.

From the entire process to see the whole process automation, without human intervention, greatly improving the service of university library service level and efficiency, reduces the time cost and the library.

\section{System principle}

Electronic borrowing principle. The borrower registered user name and password through network, and provided relevant information, the system bind the user name, password with registration campus card. At using, reader logins the platform, after authentication, reader can browse books through the book recommendation system or other mode, choose what they want to borrow, then, borrow the books through internet.

Work principle of accessing the library. The access control system has three functions when reader enters the library: reader identification, books information recognition and other related information display.

Reader ID. RFID reader of the access control systems priority identifies on campus card, user authentication, identifying algorithm uses dynamic binary search algorithm ${ }^{[7]}$; after identity verification, the gate open.

Books information recognition. With gates opening, the FRID reader reads the electronic label on books, recognition method using dynamic ALOHA method ${ }^{[8]}$. In this process there are three situations: First, scanning no books tag information (reader does not carry any books), gate automatically close after reader entered; Second, scanning one RF tag (reader carries one book), after radio frequency label into the transmission antenna work area of RFID reader, the electronic tag is activated. The RF tag will send out own coding information through the built-in antenna; after the system receive the carrier signal from the RF tag by a receiving antenna, the information correlation processed was send to information management center. After the user enters the gate closed. When the book was placed on the self-service platform the information center send instructions to change the status of this book. Third, scanning two or more RF tag (reader carrying two or more books), to avoid data packet collisions in reading, system using dynamic ALOHA method to correctly read all the tags, and do corresponding processing. 
Information display. Information display in two parts, one part is the reader's basic information, including user names, other personal information and the allowing books number again; another part displays the information of the position placed pre-borrowing books on the self-service platform, according to the position information reader can self-service take the books at the platform.

The working principle of out library. The access control system complete reader identification, books information confirmation, and alarm functions.

Reader ID. Like access, card reader priority identifies campus card using dynamic binary search algorithm, then identifies books label using dynamic ALOHA method, check for carrying books.

Books borrowing information confirmation. reader scanning no any tag information, namely, the person doesn't borrow, gates open, while examining the pre-borrow information of the reader, if they has pre-borrowing information, the state is removed, if no, without any treatment, after the reader out, the gates close. Otherwise, the card reader automatically scanning and reading the information of the books borrowed by reader with the labels, and statistics the number of borrowed books. If the number exceeds lending limit, trigger alarm, at the same time display converted to prompt screen; if there is no limit, the reader sends commands to the information management center to modify the status information of the books, remove pre-borrowing information, and other related registration. At the same time the gate is opened, after the reader out gate close, display automatic updates, waiting for the next reader.

Anti-collision theory. For remote RF identification system, when there is more than one radio frequency tag in work area of the reader, since all of the RF tag working in the same frequency, the data of RF tag can not be identified correctly with the RF tag data collision in the card reader. To avoid a collision occur, the system uses the dynamic ALOHA method put forward in paper [8], the RFID anti-collision method was constructed based on the mathematical characteristics of collision problem itself. Collision probability is dependent on three parameters: the interval time of label message transmit, the data frame length of the transmit information and the RF tag number within the work area of the reader. The method detects conflict exist through some data encoding, dynamically adjusts the alarm time of the reader, thereby achieves the reducing of the received error rate of the data frame to the required level. In the method neither the detection mechanism nor the recovery mechanism, at the same time without reducing the RF tag data swallow-spit rate. Using this method, the RF tag and reader only need transmitting and receiving equipment respectively, this means that the cost is greatly reduced.

\section{The system implementation and Application.}

The system design mainly includes the control program module and information management database.

The control program module uses $\mathrm{C}$ language, function including communications handshake, data transmission, data receiving, decoding error correction, interrupt service, RS232 communication, data reading and controlling peripheral equipment.

The database uses the Oracle relational database, developed by $\mathrm{VC}++$ and $\mathrm{SQL}$ language. The main modules includes database establishment, the resource management. At the same time developed the data interface of receiving and sending data from reader.

After the system implement, the system was installed in a university library, there are more than 24000 students and more than 1500 teachers in the university, and the collection of books is more than 2 million in the library.

Before the system installation, the average time of borrow book in library need 50 to 90 minutes, mainly used for the selection of books and queuing. The returning book also takes 10 minutes, mainly used for queuing and scanning.

After the system application, most people are used to select and borrow books online, the time of spending on taking and returning books reduces to 5minutes. Greatly improve the quality and efficiency of Library services. 


\section{Conclusion and prospect.}

In conclusion, colleges and universities library is the important source of information for teachers and students, it plays a decisive role on the university development, construction, the implement of the system is great significance to digital library in Colleges and universities, improves support for the university library digital construction. Specific advantages as following:

- RFID technology and electronic label has the advantages of environmental adaptation ability, long service life, one-time investment and low cost;

- RFID technology is non-contact identification and process automation, improving the efficiency, quality and level of library services;

- The system improves the integration level of the library collaborative commerce.

\section{Acknowledgement}

National Natural Science Foundation (61163035)

Natural Science Foundation of Yunnan Province （2009ZC087M）

\section{References}

[1] Yan Feng, Wang Ling, Li Ruohui. The existing problems and solutions of the popularization for RFID in small and medium library [J]. Journal of medical informatics, 2011, 32(10):72-75.

[2] Peng Shanglian, Li Zhanhuai, Li Qiang, Chen Qun. Detection of complex event over RFID data streams with multi-levels [J]. J. Huazhong Univ. of Sci. \& Tech. (Natural Science Edition), 2011, 39(7):54-59.

[3] Derakhshan R, Orlowska M E. , Li X.. RFID data management: challenges and opportunities [C]. IEEE International conference on RFID Grapevine: IEEE Computer society, 2007:175-182.

[4] Chen Q, Li Z, H. Optimizing complex event processing over RFID data streams [C]. Proc. Of IEEE ICDE Conf. Cancun: IEEE, 2008:1442-1444.

[5] Liao Guoqiong, Li Jing. Distance-based outlier detection for distributed RFID date streams [J]. Journal of computer research and development, 2010, 47(5):930-939.

[6] Zhang Yuanyuan, Liu Jingao. Design of intelligent management system of digital library based on RFID [J]. Journal of electron devices, 2007, 30(3):926-930.

[7] Fin kenz ell er, K. RFID H an dbook Fundament als and Appl ications in Cont act less Smart Cards and Ident ificat ion. German y[ J ] . Carl HANSER Verlag, 2000.

[8] Wu Chunhua, Chen Jun. Application of Dynamic ALOHA in RFID's Collision [J]. Journal of electron devices, 2003, 20(6):72-76. 